\title{
Pediatric EM
}

\section{Variation in the use of skull radiographs by emergency physicians in young children with minor head trauma}

\author{
Benoit Carrière, MD, MHPE; Karine Clément, MD; Jocelyn Gravel, MD, MSc
}

\section{ABSTRACT}

Background: Minor head trauma in young children is a major cause of emergency department visits. Conflicting guidelines exist regarding radiologic evaluation in such cases.

Objective: To determine the practice pattern among Canadian emergency physicians for ordering skull radiographs in young children suffering from minor head trauma. Physicians were also surveyed on their willingness to use a clinical decision rule in such cases.

Design/Methods: A self-administered email questionnaire was sent to all members of the Pediatric Emergency Research Canada (PERC) group. It consisted of clinical vignettes followed by multiple-option answers on the management plan. The study was conducted using the principles of the Dillman Tailored Design method and included multiple emailings to maximize the response rate. The research protocol received Institutional Review Board approval.

Results: A total of 158 of 295 (54\%) PERC members responded. Most participants were trained in pediatric emergency medicine and assessed more than 500 children per year. Imaging management for the vignettes was highly variable: 6 of the 11 case scenarios had a proportion of radiograph ordering between 20 and $80 \%$. Ninety-five percent of respondents stated that they would apply a validated clinical decision rule for the detection of skull fracture in young children with minor head trauma. The minimum sensitivity deemed acceptable for such a rule was $98 \%$.

Conclusion: Canadian emergency physicians have a wide variation in skull radiography ordering in young children with minor head trauma. This variation, along with the need expressed by physicians, suggests that further research to develop a clinical decision rule is warranted.

\section{RÉSUMÉ}

Contexte: Les traumas crâniens légers chez les jeunes enfants sont une cause importante de consultations au service des urgences. Toutefois, les lignes directrices sur
I'évaluation radiologique de ce type de lésions sont contradictoires.

Objectif: L'étude visait à déterminer la pratique quant aux demandes de radiographie du crâne, par les urgentologues, au Canada, chez les jeunes enfants ayant subi un trauma crânien léger. Une enquête a également été menée sur la disposition des médecins à appliquer une règle de décision clinique dans la prise en charge de ces cas.

Plan d'étude/Méthodes: Un questionnaire électronique, à remplir soi-même a été envoyé à tous les membres du Groupe de Recherche en Urgence Pédiatrique du Canada (PERC). Le questionnaire consistait en de courts scénarios cliniques, suivis de réponses à choix multiples sur le plan de traitement. L'étude a été menée selon les principes de la méthode de conception adaptée de Dillman, et plusieurs rappels ont été faits par courriel afin de maximiser le taux de réponse. Le protocole de recherche a obtenu l'approbation du comité d'examen de l'établissement.

Résultats: Au total, 158 membres du PERC sur 295 (54\%) ont répondu au questionnaire. La plupart des participants avaient une formation en médecine d'urgence pédiatrique et évaluaient plus de 500 enfants par année. La demande d'examens par imagerie était très variable; en effet, la proportion de demandes de radiographie variait de $20 \%$ à $80 \%$ dans 6 scénarios sur 11. Par ailleurs, 95\% des répondants se sont dits disposés à appliquer une règle de décision clinique validée relativement à la détection des fractures du crâne chez les jeunes enfants ayant subi un trauma crânien léger. La sensibilité minimale jugée acceptable pour ce genre de règle était de $98 \%$.

Conclusion: La demande de radiographies du crâne, par les urgentologues, chez les jeunes enfants ayant subi un trauma crânien léger varie énormément au Canada. L'ampleur de l'écart permet de croire qu'une recherche approfondie sur l'élaboration d'une règle de décision clinique est justifiée, d'autant plus que les médecins conviennent de sa nécessité.

Keywords: head trauma, pediatrics, skull radiograph, survey

From the Division of Emergency Medicine, Department of Paediatrics, CHU Sainte-Justine, Université de Montréal, Montréal, QC.

Correspondence to: Dr. Benoit Carrière, Division of Emergency Medicine, Department of Paediatrics, CHU Sainte-Justine, 3175 Chemin Côte Sainte-Catherine, Montreal, QC H3T 1C5; benoitcarriere@mac.com.

This article has been peer reviewed. 
Head injury accounts for about 400,000 emergency department (ED) visits per year in children under age 14 in the United States. ${ }^{1}$ Minor head trauma is diagnosed in the majority of these cases and has a peak incidence in children younger than 5 years old. ${ }^{2}$ Minor head trauma in young children has been defined as a history or signs of blunt trauma to the scalp, skull, or brain in a patient who is alert or awakens to voice or light touch. ${ }^{3}$ The main challenge in the ED management of children with minor head trauma is to determine who is at risk for complications and requires diagnostic imaging for the possibility of an intracranial lesion and/or skull fracture. About 3 to $6 \%$ of children suffering from minor head trauma will have intracranial injury. ${ }^{4-10}$ In a systematic review by Maguire and colleagues, the need for neurosurgical intervention in children with minor head trauma varied from 0.2 to $0.6 \% .{ }^{11}$ These observations underline the importance of reliable features to identify children at risk for such complications. Skull fracture has an incidence of 3.5 to $14 \%$ and is more common among children under 2 years of age. ${ }^{10,12-14}$ The importance of detecting isolated skull fracture arises from the fact that depressed fractures or those with large diastasis require neurosurgical evaluation and, in some cases, surgical intervention. ${ }^{15-18}$

Controversy exists on the usefulness of skull radiographs in children less than 2 years of age with minor head trauma. Although cerebral computed tomography (CT) has become the imaging modality of choice to evaluate an intracranial injury in the ED setting, it is clear that not all young children with minor head trauma require a CT scan. ${ }^{19}$ The long-term negative effects of ionizing radiation, potential for complications from procedural sedation, and costs have led several research teams to develop guidelines for CT scan use in such situations. ${ }^{20-24}$ However, none of these guidelines address what is arguably the most frequent situation faced by emergency physicians: a young child with minor head trauma and no evidence of brain injury who does not meet the criteria for head CT.

Over the last decade, conflicting guidelines have been implemented for the use of skull radiographs., ${ }^{3,24,25}$ For example, the American Academy of Pediatrics guideline states that skull radiography should be considered in a number of situations, including the presence of a scalp hematoma (particularly if nonfrontal) and a fall onto a hard surface. ${ }^{3}$ In contrast, the National Institute for Health and Clinical Excellence (NICE) guidelines state that skull radiography should be performed only when nonaccidental injury is suspected..$^{25}$

Given the variation in recommendations among guidelines for minor head trauma in young children, it is conceivable that a variation in practice pattern also exists. The objectives of this study were 1) to determine the practice pattern among Canadian emergency physicians in ordering skull radiographs for young children with minor head trauma and 2) to determine if Canadian emergency physicians would use a clinical decision rule for skull radiographs in young children with minor head trauma.

\section{METHODOLOGY}

\section{Study design and setting}

Data were captured through a self-administered email questionnaire sent to physicians who were members of the Pediatric Emergency Research Canada (PERC) group. The PERC group is an association of emergency physicians with an interest in pediatric emergency medicine research from 15 institutions in nine provinces in Canada. We chose to poll PERC members because of their expertise and homogeneity. The study was coordinated by the CHU Sainte-Justine Research Institute and was carried out from October through November 2011.

\section{Participants}

Using the PERC mailing list, every member of the organization was invited to participate. Respondents who did not practice clinically, physicians in-training, and those who practiced in an adult-only setting were excluded from the analysis.

\section{Procedure}

The study investigators constructed the questionnaire. Case scenarios were developed following discussion with experts in pediatric emergency medicine. Each vignette depicted a domestic fall situation in which the child had no signs or symptoms of brain injury. Four scenarios were constructed based on cases encountered in the past by the authors. For each scenario, two or three clinical vignettes were developed by varying one clinical factor potentially associated with skull fracture risk (these included patient age, hematoma size, and location or height of the fall). 5,7,26,27 The questionnaire was developed in French and subsequently translated 
into English. It was pilot tested for clarity and proper translation in both languages among five bilingual pediatric emergency physicians. It was then posted on a Web-based survey site (surveymonkey.com).

\section{Questionnaire content}

The full questionnaire is available as an online appendix at the following URL: www.cjem-online.ca. The first part of the questionnaire consisted of 11 clinical vignettes followed by multiple-choice questions on the management plan that would be used. In the second part of the questionnaire, the respondents were asked the following questions: 1) Did they favour the development of a decision rule for the use of skull radiography in minor head trauma in young children? 2) What did they feel would be the ideal primary outcome for such a rule? and 3) How sensitive would the rule need to be in order for them to use it? Finally, we asked respondents if they currently base their clinical conduct on specific guidelines.

\section{Questionnaire administration}

The survey was conducted using the principles of the Dillman Tailored Design method. Email correspondence consisting of an introduction letter explaining the study was first sent to all potential participants. Potential participants then received a cover letter describing the study, which assured them of confidentiality and provided the questionnaire and instructions for its completion. Eligible physicians who did not respond received a total of three reminders to complete the questionnaire, each 2 weeks apart.

\section{Data collection and processing}

All data were collected electronically via surveymonkey.com and then transferred to an Excel spreadsheet (Microsoft, Richmond, WA). The analysis was carried out with SPSS version 17 (SPSS Inc., Chicago, IL).

\section{Primary outcomes}

The primary outcome was the proportion of physicians indicating that they would perform a skull radiograph for each clinical vignette. Secondary outcomes included the proportion of physicians indicating that they would agree to use a validated clinical decision rule, the primary outcome most physicians would find useful for a clinical rule, and the sensitivity deemed to be necessary for such a rule.

\section{Analysis}

This was an observational study. For each of the 11 clinical vignettes, the proportion of radiographs ordered was determined. A priori, it was established by the research team that clinical management in a given scenario would be considered homogeneous if more than $80 \%$ of respondents indicated the same approach. Accordingly, a proportion of radiographs that varied from 20 to $80 \%$ would be classified as variable. For example, if more than $80 \%$ of the respondents indicated that they would obtain a CT scan for the patient, or if less than $20 \%$ would obtain a skull radiograph, then the clinical vignette would be deemed to be of low variability.

Proportions with $95 \%$ confidence intervals were calculated for all results.

\section{Ethics}

The protocol was approved by the Institutional Review Board of the CHU Sainte-Justine Research Institute, and consent was deemed to be implied for participants who responded to the survey.

\section{RESULTS}

Of 306 PERC members in the database, 11 were excluded (3 did not have valid email addresses, 6 had their email accounts blocking the survey website, and 2 requested removal). An invitation was thus submitted to 295 PERC members, of whom 158 (54\%) agreed to participate. The demographic characteristics of the study participants are provided in Table 1 . Fifty-seven percent of the participants were trained in pediatric emergency medicine, $85 \%$ evaluated more than 500 children per year, and $83 \%$ worked in a dedicated pediatric ED. Respondents were distributed from across Canada. Fifty-one percent of the participants reported that they currently use a clinical algorithm for the evaluation of head trauma in young children, with the CATCH rule ${ }^{19}$ being cited the most often. The CATCH rule was derived and validated to help clinicians with decisions on CT-scan criteria for children with minor head trauma. 


\begin{tabular}{|c|c|}
\hline Characteristic & $n(\%)$ \\
\hline \multicolumn{2}{|l|}{ Age group (yr) } \\
\hline Under 30 & $3(2)$ \\
\hline 30-39 & $60(38)$ \\
\hline $40-49$ & $54(34)$ \\
\hline $50-59$ & $26(17)$ \\
\hline 60 and older & $9(6)$ \\
\hline Missing & $6(3)$ \\
\hline \multicolumn{2}{|l|}{ Sex } \\
\hline Male & $72(46)$ \\
\hline Female & $79(51)$ \\
\hline Missing & $7(4)$ \\
\hline \multicolumn{2}{|l|}{ Medical training } \\
\hline Family medicine & $3(2)$ \\
\hline $\begin{array}{l}\text { Family medicine + emergency } \\
\text { medicine }\end{array}$ & $12(8)$ \\
\hline Pediatrics & $32(21)$ \\
\hline Emergency medicine & $14(9)$ \\
\hline Pediatric emergency medicine & $89(56)$ \\
\hline Other & $2(1)$ \\
\hline Missing & $6(4)$ \\
\hline \multicolumn{2}{|l|}{ Clinical experience (yr) } \\
\hline$<10$ & $67(43)$ \\
\hline $11-20$ & $50(32)$ \\
\hline$>20$ & $35(22)$ \\
\hline Missing & $6(4)$ \\
\hline \multicolumn{2}{|l|}{ Type of hospital practice } \\
\hline Community/general & $17(11)$ \\
\hline Pediatric emergency department & $132(84)$ \\
\hline Missing & $9(5)$ \\
\hline \multicolumn{2}{|l|}{ Number of children seen annually } \\
\hline Between 10 and 500 & $15(9)$ \\
\hline Between 501 and 1,000 & $20(13)$ \\
\hline$>1,000$ & $115(73)$ \\
\hline Missing & $8(6)$ \\
\hline
\end{tabular}

\section{Skull radiograph ordering}

Examples of two case scenario vignettes and responses are provided in the Appendix. Depending on the clinical scenario presented, physicians indicated that they would obtain skull radiographs in proportions that varied from 1 to $51 \%$ (Figure 1). The obtaining of skull radiographs was highly variable: 6 of the 11 case scenarios had a proportion of skull radiographs ranging from 20 to $80 \%$. In 10 of the 11 case scenarios, a lower proportion of participants indicated that they would obtain a CT scan rather than a skull radiograph. Significant variability in the proportion of participants ordering a CT scan was also found, with four scenarios having a proportion of CT scan ordering over $10 \%$.
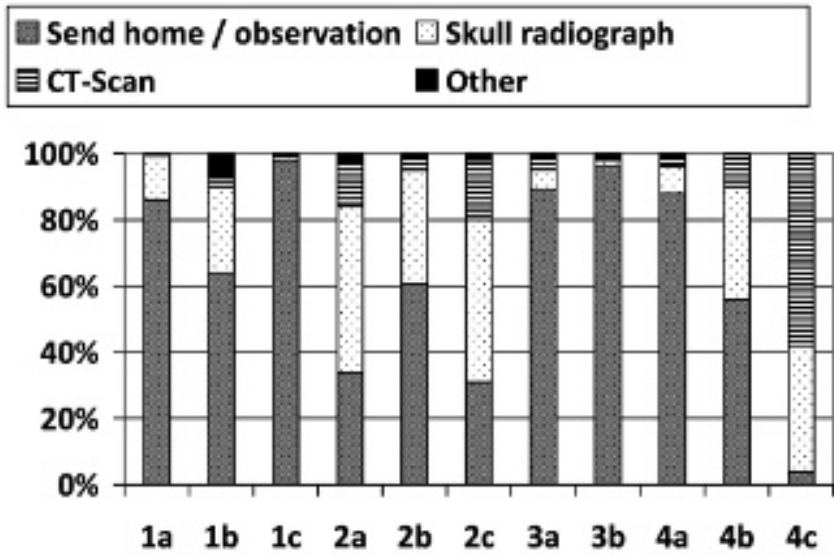

Figure 1. Management choices regarding the use of skull or brain imagery by participants for the 11 clinical vignettes ( $n=158$ evaluations for each scenario). CT = computed tomographic.

\section{Skull fracture management}

Two scenarios were designed to evaluate the management of a known skull fracture. Fifty-four percent of the participants indicated that they would perform CT on a well-looking 3-month-old baby who had sustained a parietal skull fracture after falling from the couch, and $29 \%$ indicated that they would hospitalize the baby because of the fracture. When presented with a fracture with a diastasis of $5 \mathrm{~mm}, 70 \%$ participants indicated that they would obtain a CT scan and 19\% indicated that they would hospitalize.

\section{Clinical decision rule use}

Ninety-five percent of the respondents reported that they would use a validated clinical decision rule regarding the use of skull radiography for the detection of skull fractures in young children with minor head trauma. In $92 \%$ of the respondents, a clinical decision rule with a sensitivity of $98 \%$ or higher was deemed to be sufficient for use. There were varied responses on what primary outcomes such as a clinical decision rule identify.

\section{DISCUSSION}

The results of this study indicate that significant practice variation exists among Canadian emergency physicians regarding obtaining skull radiographs in young children with minor head trauma. Respondents indicated a willingness to use a highly sensitive clinical 
decision rule to improve and standardize the use of skull radiograph for this population.

To our knowledge, this is the first study to evaluate the practice pattern regarding the use of skull radiographs in young children with minor head trauma. The results of our questionnaire suggest that many physicians continue to order skull radiographs in this situation, despite existing guidelines indicating that their use should be limited., ${ }^{3,2}$ In 2001, the American Academy of Pediatrics published guidelines for the management of children younger than 2 years old with minor head injury. ${ }^{3}$ These guidelines were based primarily on expert opinion because few studies have been conducted on the subject. The guidelines indicate that skull radiographs should be considered in higherforce mechanisms of injury, when a scalp hematoma is present (particularly if nonfrontal), in falls onto a hard surface, in unwitnessed trauma with the possibility of a significant mechanism, and in vague situations or an absence of history of trauma in a child with signs or symptoms of head trauma. In 2007, the NICE published evidence-based guidelines regarding head injury stating that a skull radiograph should be performed only when nonaccidental injury is suspected. ${ }^{25}$ In a retrospective chart analysis, Beaudin and colleagues reported that restricting the use of skull radiography in children younger than 3 years old to those with cephalohematoma, a major fall, a penetrating wound, or a suspicion of child abuse appears to be a safe and resource-effective practice. ${ }^{24}$

Controversy exists on the usefulness of skull radiography in the specific context of minor head trauma in children less than 2 years of age, in large part because skull radiographs cannot reliably detect intracranial injury. A meta-analysis conducted in 2004 by Dunning and colleagues found that finding a skull fracture on a plain radiograph had a sensitivity of $59 \%$ and a specificity of $88 \%$ for the detection of intracranial lesions. ${ }^{23}$ This low sensitivity makes radiography a poor screening tool for intracranial lesions. The meta-analysis included studies of children less than 18 years of age, and it is conceivable that the findings may be different in subgroups less than 2 years of age. Other studies indicate that 15 to $30 \%$ of patients less than 2 years of age with a skull fracture detected on plain radiographs have an intracranial injury. ${ }^{3,22,25}$ Some authors even suggested that in young children, the presence of a skull fracture is a better predictor of intracranial injury than anomalies on physical examination. ${ }^{3}$
Two of the main advantages of skull radiography in contrast to head CT are the low radiation involved and the lack of a requirement for sedation. In addition, certain linear skull fractures not detected on a CT scan can be seen on a skull radiograph. This can be particularly important when nonaccidental injury is suspected or in occult fractures that require neurosurgical evaluation. The potential usefulness of skull radiographs lies in their correct interpretation. One study found that emergency physicians interpreted skull radiographs correctly in only $65 \%$ of cases. ${ }^{28}$ This finding makes it difficult to rely on skull radiograph results interpreted by emergency physicians to guide subsequent clinical management.

The general agreement we found among participants regarding willingness to use a clinical decision rule for skull radiographs in young children with minor head trauma is another important finding. Although in theory not a sine qua non prerequisite for the development of a clinical decision rule, the advance knowledge that clinicians would indeed use a rule is important. Participants were pragmatic and acknowledged that although high sensitivity was a prerequisite, a clinical decision rule did not have to be perfect. Almost all participants indicated that they would use a rule with a sensitivity of $98 \%$ or higher.

\section{LIMITATIONS}

The main limitation of our study relates to the response rate of $54 \%$. This was lower than we expected; however, it is comparable to many physician surveys. ${ }^{29}$ It is conceivable that enrolment bias may have existed, and, for example, nonrespondents might have managed the questionnaire situations more consistently. Our sampling method used the PERC database, leading to an overrepresentation of pediatric emergency medicine physicians, which again could have biased our results, likely toward better agreement as such physicians are arguably medical experts in the field of minor head trauma. Given this, it is possible that the actual practice in Canada is even more variable than we found. As with all surveys, our results are limited by the fact that what is actually done by respondents is unknown, and we can only be confident about what they stated they would do in in the scenarios presented. Finally, we did not investigate the use of ultrasonography or the increasing accessibility of low-dose or ultra-low-dose CT. As these modalities 
are becoming increasingly available in Canadian emergency departments, they will likely become another option for the evaluation of young children with minor head trauma.

\section{CONCLUSION}

Canadian emergency physicians have a wide variation in skull radiograph ordering in young children with minor head trauma. This variation, along with the need expressed by physicians, suggests that further research to develop a clinical decision rule is warranted.

Competing interests: None declared.

\section{REFERENCES}

1. Haydel MJ, Shembekar AD. Prediction of intracranial injury in children aged five years and older with loss of consciousness after minor head injury due to nontrivial mechanisms. Ann Emerg Med 2003;42:507-14, doi:10.1067/S0196-0644 (03)00512-2.

2. Bazarian JJ, McClung J, Shah MN, et al. Mild traumatic brain injury in the United States, 1998-2000. Brain Inj 2005; 19:85-91, doi:10.1080/02699050410001720158.

3. Schutzman SA, Barnes P, Duhaime AC, et al. Evaluation and management of children younger than two years old with apparently minor head trauma: proposed guidelines. Pediatrics 2001;107:983-93, doi:10.1542/peds.107.5.983.

4. Schunk JE, Rodgerson JD, Woodward GA. The utility of head computed tomographic scanning in pediatric patients with normal neurologic examination in the emergency department. Pediatr Emerg Care 1996;12:160-5, doi:10. 1097/00006565-199606000-00004.

5. Quayle KS, Jaffe DM, Kuppermann N, et al. Diagnostic testing for acute head injury in children: when are head computed tomography and skull radiographs indicated? Pediatrics 1997;99:E11, doi:10.1542/peds.99.5.e11.

6. Ramundo ML, McKnight T, Kempf J, Satkowiak L. Clinical predictors of computed tomographic abnormalities following pediatric traumatic brain injury. Pediatr Emerg Care 1995;11:1-4, doi:10.1097/00006565-199502000$\underline{00001}$.

7. Gruskin KD, Schutzman SA. Head trauma in children younger than 2 years: are there predictors for complications? Arch Pediatr Adolesc Med 1999;153:15-20, doi:10.1001/archpedi. 153.1.15.

8. Stewart G, Meert K, Rosenberg N. Trauma in infants less than three months of age. Pediatr Emerg Care 1993;9:199201, doi:10.1097/00006565-199308000-00004.

9. Dietrich AM, Bowman MJ, Ginn-Pease ME, et al. Pediatric head injuries: can clinical factors reliably predict an abnormality on computed tomography? Ann Emerg Med 1993;22:1535-40, doi:10.1016/S0196-0644(05)81254-5.

10. Boulis ZF, Dick R, Barnes NR. Head injuries in children-aetiology, symptoms, physical findings and x-ray wastage. $\mathrm{Br} f$ Radiol 1978;51:851-4, doi:10.1259/ 0007-1285-51-611-851.

11. Maguire JL, Boutis K, Uleryk EM, et al. Should a headinjured child receive a head CT scan? A systematic review of clinical prediction rules. Pediatrics 2009;124:e145-54, doi:10.1542/peds.2009-0075.

12. Reed MJ, Browning JG, Wilkinson AG, Beattie T. Can we abolish skull x rays for head injury? Arch Dis Child 2005;90: 859-64, doi:10.1136/adc.2004.053603.

13. Leonidas JC, Ting W, Binkiewicz A, et al. Mild head trauma in children: when is a roentgenogram necessary? Pediatrics 1982;69:139-43.

14. Ros SP, Cetta F. Are skull radiographs useful in the evaluation of asymptomatic infants following minor head injury? Pediatr Emerg Care 1992;8:328-30, doi:10.1097/ 00006565-199212000-00005.

15. Ersahin Y, Gulmen V, Palali I, Mutluer S. Growing skull fractures (craniocerebral erosion). Neurosurg Rev 2000;23: 139-44, doi:10.1007/PL00011945.

16. Ersahin Y, Mutluer S, Mirzai H, Palali I. Pediatric depressed skull fractures: analysis of 530 cases. Childs Nerv Syst 1996; 12:323-31, doi:10.1007/BF00301021.

17. Pezzotta S, Silvani V, Gaetani P, et al. Growing skull fractures of childhood. Case report and review of 132 cases. 7 Neurosurg Sci 1985;29:129-35.

18. Gupta SK, Reddy NM, Khosla VK, et al. Growing skull fractures: a clinical study of 41 patients. Acta Neurochir (Wien) 1997;139:928-32, doi:10.1007/BF01411301.

19. Osmond MH, Klassen TP, Wells GA, et al. CATCH: a clinical decision rule for the use of computed tomography in children with minor head injury. CMAJ 2010;182: 341-8.

20. King MA, Kanal KM, Relyea-Chew A, et al. Radiation exposure from pediatric head CT: a bi-institutional study. Pediatr Radiol 2009;39:1059-65, doi:10.1007/s00247-0091327-1.

21. Stein SC, Hurst RW, Sonnad SS. Meta-analysis of cranial CT scans in children. A mathematical model to predict radiation-induced tumors. Pediatr Neurosurg 2008;44:448-57, doi:10.1159/000172967.

22. Palchak MJ, Holmes JF, Vance CW, et al. A decision rule for identifying children at low risk for brain injuries after blunt head trauma. Ann Emerg Med 2003;42:492-506, doi:10.1067/S0196-0644(03)00425-6.

23. Dunning J, Daly JP, Lomas JP, et al. Derivation of the children's head injury algorithm for the prediction of important clinical events decision rule for head injury in children. Arch Dis Child 2006;91:885-91, doi:10.1136/ adc. 2005.083980.

24. Beaudin M, Saint-Vil D, Ouimet A, et al. Clinical algorithm and resource use in the management of children with minor head trauma. 7 Pediatr Surg 2007;42:849-52, doi:10.1016/ j.jpedsurg.2006.12.038.

25. National Collaborating Centre for Acute Care. Head injury. Triage, assessment, investigation and early management of head injury in infants, children and adults. London, UK: National Institute for Health and Clinical Excellence; 2007.

26. Greenes DS, Schutzman SA. Infants with isolated skull fracture: what are their clinical characteristics, and do they 
require hospitalization? Ann Emerg Med 1997;30:253-9, doi:10.1016/S0196-0644(97)70158-6.

27. Greenes DS, Schutzman SA. Clinical significance of scalp abnormalities in asymptomatic head-injured infants. Pediatr Emerg Care 2001;17:88-92, doi:10.1097/00006565-20010400000002 .

28. Chung S, Schamban N, Wypij D, et al. Skull radiograph interpretation of children younger than two years: how good are pediatric emergency physicians? Ann Emerg Med 2004; 43:718-22, doi:10.1016/j.annemergmed.2003.09.020.

29. Asch DA, Jedrziewski MK, Christakis NA. Response rates to mail surveys published in medical journals. 7 Clin Epidemiol 1997;50:1129-36, doi:10.1016/S0895-4356(97)00126-1.

\section{APPENDIX: TWO EXAMPLE CASE SCENARIO VIGNETTES AND RESPONSES}

A 5-month-old baby fell off her parents' bed on the carpet. She cried immediately. There was no loss or alteration of consciousness. The incident happened 3 hours ago. Since then, the child has drunk her milk like usual. There was no vomiting or seizure. On physical examination, you note a tender parietal hematoma of $3 \mathrm{~cm}$ in diameter. The child is smiling except when you touch the hematoma.
What would you do initially? (one answer allowed)

$\begin{array}{lc}\text { Send home with advice on minor head trauma } & 26(16 \%) \\ \text { Observation without imaging } & 26(16 \%) \\ \text { Skull radiograph } \pm \text { observation } & 81(51 \%) \\ \text { CT scan of the head } \pm \text { observation } & 21(13 \%) \\ \text { Other } & 4(3 \%)\end{array}$

Three hours ago, the father of an 8-month-old baby fell from his height with his child in his arms. He thinks that the head of the child hit the floor first. The baby cried immediately. There was no loss or alteration of consciousness, vomiting, or seizure. On physical examination, the skull shows a $1 \mathrm{~cm}$ parietal hematoma, and a neurologic examination is normal. The child is calm but not smiling.

What would you do initially? (one answer allowed)

$\begin{array}{ll}\text { Send home with advice on minor head trauma } & 28(18 \%) \\ \text { Observation without imaging } & 57(38 \%) \\ \text { Skull radiograph } \pm \text { observation } & 52(34 \%) \\ \text { CT scan of the head } \pm \text { observation } & 15(10 \%) \\ \text { No response } & 6\end{array}$

